\title{
2015: O ANO DE TRISTE MEMÓRIA PARA O DIREITO FINANCEIRO QUE NÃO QUER TERMINAR
}

Coluna publicada em 15.12.2015: < http://www.conjur.com.br/ 2015-dez-15/contas-vista-2015-ano-nao-terminar $>$

Este ano de 2015, já próximo do fim, está sendo de triste memória para o Direito Financeiro.

Começou mal, como destaquei em coluna publicada no início do ano, ${ }^{1}$ e está a poucos dias de terminar tão mal ou pior do que começou.

Faltando praticamente uma semana para o encerramento da sessão legislativa do Congresso Nacional, ainda não foram aprovados o Plano Plurianual 2016-2019 e o Orçamento da União para 2016, tudo indicando que não será novamente cumprido o prazo. Pior se verifica em relação à Lei de Diretrizes Orçamentárias LDO, cujo prazo expirou em julho, e está caminhando para quebrar o recorde do ano passado, em que acabou sendo aprovada no exercício seguinte.

E é pouco provável a aprovação do orçamento ou mesmo do Plano Plurianual, leis que geram debates intensos e tendem a não conseguir aprovação em épocas de difícil consenso, tal como a que se apresenta agora, em que os ânimos se acirraram e a votação do impeachment tende a ocupar a agenda política.

A menos que se concretize o alegado esforço concentrado anunciado para essa semana, ${ }^{2}$ corremos o risco de ficar sem as três leis que regulam o planejamento financeiro da administração pública federal, com reflexos no país inteiro, pois os entes subnacionais dependem fortemente das transferências intergovernamentais, tendo em vista nosso regime de federalismo cooperativo.

1 O direito financeiro precisa ser levado a sério, e 2015 começou mal, publicada em 10 de fevereiro de 2015, no site do Conjur.

2 Congresso Nacional terá "super semana" de votaçôes. O Estado de S.Paulo, em 12 de dezembro de 2015. 
Uma mostra de descaso com o planejamento, já denunciado em coluna anterior, ${ }^{3}$ que se perpetua e se agrava, com a falta de rumos do governo federal contaminando os demais entes da federação e impedindo que possam ser conduzidos de modo minimamente eficiente.

Da Lei do Plano Plurianual - PPA pouco se falou por ocasião da apresentação do seu projeto e raras são as referências a ela, às vésperas da data em que deveria ser aprovada, ${ }^{4}$ o que evidencia não estar merecendo atenção. E é hoje não apenas o principal instrumento de planejamento da administração pública federal, mas de todo o país, ante a falta de leis que regulem o planejamento em âmbito nacional no médio e longo prazos. É alvissareira a notícia de que o projeto de PPA, ao menos, foi aprovado recentemente na Comissão Mista de Planos, Orçamentos Públicos e Fiscalização (CMO), e alinhado ao Plano Nacional de Educação - o mínimo que se espera de um governo que almeja ser o da "Pátria Educadora", embora os fatos, especialmente a constante troca de ministros da área, mitiguem a credibilidade dessa afirmação. 5

Vê-se que o governo federal, ao que tudo indica, concentra todas as suas energias em tentar manter-se no poder, sem ter ideia do que fazer com ele. Se, como já mencionei anteriormente, governar sem um planejamento sério é como comandar um transatlântico no oceano sem mapa e instrumentos de navegação, e desconhecendo até mesmo o porto de destino, ${ }^{6}$ o que se vê atualmente é já existirem inúmeros furos no casco, sendo a preocupação tão somente de não afundar, pouco importando para onde ir.

Um dos mais lamentáveis atos praticados no final do ano passado, por incrível que pareça, volta a se repetir: a modificação da Lei de Diretrizes Orçamentárias às vésperas do final do exercício financeiro, para evitar que seja considerada violada. A LDO que fixou as diretrizes e metas para 2014 (Lei n. 12.919, de 24.12.2013), em cumprimento à Lei de Responsabilidade Fiscal, estabeleceu a meta de superávit pri-

3 Descaso com o planejamento deixa o país sem rumo, publicada em 22 de setembro de 2015, no site do Conjur.

4 Constituição, Ato das Disposições Constitucionais Transitórias, art. 35, $\$ 2^{\circ}$, I: "o projeto do plano plurianual, para vigência até o final do primeiro exercício financeiro do mandato presidencial subsequente, será encaminhado até quatro meses antes do encerramento do primeiro exercício financeiro e devolvido para sanção até o encerramento da sessão legislativa”.

5 Comissão aprova PPA 2016-2019 alinhado ao Plano Nacional de Educação. Senado FederalPortal de Notícias, em 8 de dezembro de 2015.

6 Coluna Planejamento municipal precisa ser levado a sério, publicada em 24 de setembro de 2013, no site do Conjur. 
mário para o orçamento de 2014 em R $\$ 116$ bilhões; em 15 de dezembro, poucos dias antes do fim do ano, a meta é substancialmente reduzida pela Lei n. 13.053.

Neste final de ano, os fatos reproduziram-se tal e qual! A LDO para 2015 (Lei n. 13.080, de 2.1.2015) estabeleceu a meta de superávit primário em $\mathrm{R} \$ 66$ bilhões, e, novamente constatada a inviabilidade de ser atingida, no apagar das luzes, é transformada em meta de resultado deficitário de $\mathrm{R} \$ 49$ bilhôes pela Lei 13.199, publicada em 3 de dezembro de 2015.

Em abril deste ano, em cumprimento ao prazo constitucional, ${ }^{8}$ foi apresentado o projeto de LDO para 2016, que deveria ter sido aprovado em julho, justamente para balizar a elaboração do orçamento, cujo projeto é apresentado no final de agosto. Nesta LDO, foi proposta a meta de superávit primário de R \$ 104 bilhões (orçamentos fiscal e da seguridade social); a LDO, no entanto, não foi aprovada ainda, o projeto de lei orçamentária já foi encaminhado, e não se cogita mais desses valores. E a todo momento surgem notícias de novos números, evidenciando descontrole e insegurança.?

Se os fatos ora relatados são de difícil compreensão para os leigos no tema, não se assustem, pois o que se vê é realmente o caos.

E o que se pode esperar, a partir de hoje, quanto à previsão das metas fiscais que cabe à LDO estabelecer, cumprindo o que determina a LRF? Qual o valor, credibilidade e segurança jurídica terá esse dispositivo de lei daqui para frente, quando foi flagrantemente afrontado e desconsiderado por dois anos seguidos? Pensando bem, talvez não seja algo de surpreender, partindo da Presidente que parece não compreender o significado do que é uma meta: "Não vamos colocar meta. Vamos deixar a meta aberta, mas quando atingirmos a meta, vamos dobrar a meta" (Dilma Rousseff, fazendo referência ao Pronatec - programa de qualificação profissional, em agosto).

A LDO representa hoje um importante instrumento de planejamento governamental e de gestão financeira, como já ressaltado anteriormente. ${ }^{10}$ É uma lei de

7 Sobre esse assunto, veja-se a coluna Acabar com a meta de superávit é irresponsabilidade fiscal, publicada em 18 de novembro de 2014.

8 Constituição, Ato das Disposições Constitucionais Transitórias, art. 35, § 20, II: "o projeto de lei de diretrizes orçamentárias será encaminhado até oito meses e meio antes do encerramento do exercício financeiro e devolvido para sanção até o encerramento do primeiro período da sessão legislativa”.

9 Apesar das queixas de Levy, Dilma estuda redução da meta fiscal de 2016. O Estado de S.Paulo em 12 de dezembro de 2015.

10 Coluna LDO é instrumento eficiente para a administração pública, publicada em 9 de abril de 2013, no site do Conjur. 
validade temporal limitada, dada sua função precípua de estabelecer as diretrizes e metas para o exercício financeiro seguinte, orientando a elaboração da lei orçamentária anual, e atualmente regulando algumas questões relacionadas à execução orçamentária. E, mais recentemente, assumiu relevância a fixação das metas de resultado primário. Essa curta vigência já é um dos aspectos que tornam frágil sua eficácia. No entanto, essa fragilidade tem sido elevada ao seu grau máximo, fazendo a lei beirar a inutilidade, uma vez que as atitudes recentes têm desmoralizado completamente esse diploma normativo, ante os inusitados fatos ocorridos, levando a ineficácia dessa lei a um nível insustentável, o que é de se lamentar profundamente, pois seu cumprimento é essencial para uma gestão financeira responsável.

A desconsideração das metas tem sido uma verdadeira "pá de cal" nas esperanças de que se possa dar qualquer credibilidade a essa lei tão relevante, que hoje não mais transmite um mínimo de segurança jurídica e previsibilidade à ação governamental.

São demonstrações de que a irresponsabilidade fiscal ainda persiste, agora que se completam 15 anos da publicação da Lei de Responsabilidade Fiscal, ${ }^{11}$ e neste ano o retrocesso nessa área foi evidente.

Registre-se que alteração açodada das metas não se justifica pela alegação de terem ocorrido fatos imprevisíveis, que motivassem um repentino descompasso entre a arrecadação e as despesas, pois os estudos e relatórios periódicos do próprio governo já apuravam a baixa arrecadação e elevação das despesas obrigatórias. Mesmo assim, não foram tomadas as providências previstas na Lei de Responsabilidade Fiscal e na Lei de Diretrizes Orçamentárias vigente para manter o equilíbrio das contas públicas, sendo autorizados gastos em desconformidade à legislação, extrapolando as metas fixadas, em uma demonstração de irresponsabilidade na condução das finanças públicas, ${ }^{12}$ resultando no inevitável e previsível descontrole que agora se torna público, exigindo medidas drásticas de cortes abruptos nas despesas, sem critérios, estudos ou planejamento. ${ }^{13} \mathrm{Um}$ shutdown que em nada se parece com o americano, ocorrido em 2013, pois neste o problema não era a falta de dinheiro, mas a não aprovação tempestiva da lei orçamentária ante as divergências políticas do momento.

11 Como destaquei na coluna publicada em 7 de abril de 2015: Irresponsabilidade fiscal ainda persiste, 15 anos após a publicação da lei, no site do Conjur.

12 Sem nova meta aprovada, Dilma ignora exigência de cortar R\$ 105 bi. Folha de S.Paulo, em 27 de novembro de 2105.

13 Governo confirma corte de R\$ 10 bi e paralisa a máquina federal. O Estado de S.Paulo, em 27 de novembro de 2015; Dilma cancela ida ao Japão e Vietnã e baixa decreto bloqueando gastos. Folha de S.Paulo, em 27 de novembro de 2015. 
Acrescente-se ainda que os prazos de tramitação da LDO parecem ter virado "letra morta" da Constituição, que estabelece como data-limite para sua aprovação o final do primeiro período da sessão legislativa, que deveria se encerrar em julho, mas não pode ser interrompido sem a aprovação do projeto de lei de diretrizes orçamentárias, na expressa disposição do art. $57, \$ 2^{\circ}$, da Constituição. E não parece ser o que tem ocorrido nos últimos anos, deixando entrever que o Congresso tem dado um "drible" nessa norma.

Somem-se a isso as "pedaladas" do Poder Executivo, que parecem não ter cessado, mesmo após as denúncias e apurações, ${ }^{14}$ e teremos políticos capazes de formar uma seleção que jogue um futebol muito superior àquela que deu vexame na Copa do de 2014...

O orçamento, com as indefinições na sua elaboração, sendo alterado do dia para a noite, em decisões tomadas em finais de semana, ${ }^{15}$ está se tornando pouco crível e confiável, justamente agora, que estava caminhando para deixar de ser uma "peça de ficção". Um retrocesso que diminui sua importância como instrumento de planejamento, gestão e controle da atividade financeira do Estado.

Além dessas dificuldades já descritas, que comprometem o equilíbrio das contas públicas e o controle do endividamento, ainda se perdem oportunidades de aprovar leis que poderiam promover avanços, como ocorreu recentemente com o projeto de resolução do Senado Federal que estabelecia limites globais para o montante da dívida consolidada da União. ${ }^{16}$

Em um ano marcado por "maquiagens contábeis", "pedaladas", alteraçōes frequentes de metas e outras impropriedades que parecem não cessar, uma das poucas boas notícias é, na verdade, uma má notícia: o julgamento das contas de governo pelo Tribunal de Contas da União, que resultou no parecer pela rejeição, ante as múltiplas e graves irregularidades apuradas. ${ }^{17}$ Boa notícia por demonstrar a competência técnica e independência do TCU, que realizou trabalho detalhado, minucioso e bem fundamentado, e tomou decisão contrariando os interesses da mais alta autoridade do Poder Executivo. Má notícia porque não é nada bom saber que as finanças públicas estão sendo maltratadas e a legislação desrespeitada. Bom seria

14 Como denunciou o Ministério Público de Contas junto ao TCU, e é um dos fundamentos o pedido de impeachment da Presidente.

15 Veja a já citada coluna Descaso com o planejamento deixa o país sem rumo, publicada em 22 de setembro de 2015, no site do Conjur.

16 Projeto de Resolução do Senado 84, de 2007.

17 Coluna Julgamento do TCU que reprovou contas do governo entrou para a história do Direito Financeiro, publicada em 20 de outubro de 2015 no site do Conjur e presente neste livro. 
ter recebido a notícia de que as contas foram aprovadas por uma gestão financeira competente e responsável, que infelizmente não é o caso.

Tudo leva a crer que 2016 não será um bom ano. ${ }^{18} \mathrm{~A}$ inflação atinge os dois dígitos, ${ }^{19}$ renovam-se ameaças de rebaixamento pelas agências de risco ${ }^{20}$ e as más notícias não param de se avolumar.

É para se lamentar, pois 2015 deixou muito a desejar. Espera-se que, se a profecia se cumprir no que tange à economia e desenvolvimento do país, o mesmo não ocorra com o Direito Financeiro.

Se não há muito o que se esperar no aspecto econômico, pois as esperanças de melhorar são poucas, no aspecto jurídico isso só depende dos governantes, pois o dever de respeitar o ordenamento jurídico não é algo que se sujeite à conjuntura econômica ou social.

O Direito Financeiro tem mostrado sua importância e a necessidade de que suas normas sejam cumpridas. Questôes de Direito Financeiro sustentam a argumentação que pode levar um presidente a perder seu cargo por impeachment.

Muito do que está ocorrendo é consequência do desrespeito às normas vigentes, em especial as que tratam das finanças públicas, gerando descrença, desconfiança e insegurança jurídica.

A solução é simples: basta levar o Direito Financeiro a sério.

18 Pessimismo e desesperança devem pautar ano de 2016. Folha de S.Paulo, em 29 de novembro de 2015; Muito além dos 10 bilhôes, editorial O Estado de S.Paulo, em 6 de dezembro de 2015.

19 Inflação volta aos dois dígitos pela primeira vez em 12 anos. O Estado de S.Paulo, em 10 de dezembro de 2015, p. B-3; Inflação supera dois dígitos pela $1^{\text {a }}$ vez desde 2003. Folha de $S$. Paulo, em 10 de dezembro de 2015, p. A-18.

20 Moody's ameaça rebaixar o país após piora econômica e política. Folha de S.Paulo, em 10 de dezembro de 205, p. A-15; Agência Moody's ameaça tirar grau de investimento do Brasil em até 3 meses. O Estado de S.Paulo, em 10 de dezembro de 2015, p. B-1. 